\title{
Changing Places, Changing Lives
}

\author{
Alexandra Martin \\ Allied Connect \\ Valerie Watchorn \\ Deakin University \\ Cathryn Grant \\ Architecture \& Access
}

\begin{abstract}
The built environment has long been recognised as a significant determinant of social inclusion and participation of people who experience disability. Despite existence of anti-discrimination legislation and development of the United Nations Convention on the Rights of Persons with a Disability, many individuals continue to experience inequitable access to their communities. Using a qualitative approach, this study aimed to explore the lived experiences of people who use Changing Places facilities within Victoria, Australia. Semi-structured interviews were conducted with four participants regarding their experiences of using Changing Places facilities. Findings from this study further consolidate existing research that highlight social inequities experienced by people with severe and profound physical disabilities. Findings in this preliminary study can also support the development and expansion of Changing Places facilities, not only as a means of meeting legal obligations within our community, but also as an approach towards improving social inclusion and participation of people with severe and profound physical disabilities.
\end{abstract}

Keywords: disability; accessible environment; accessibility; community; Changing Places; equity; sanitary facilities

\section{Introduction}

The United Nations Declaration of Human Rights depicts the notion of equal justice amongst all individuals, acknowledging "All humans are born free and equal in dignity and rights" as a fundamental human right (United Nations General Assembly, 1948, p. 2). However, despite this assertion, inequities to participate continue to exist amongst people who experience disability (Hammell, 2015; VicHealth, 2012). These inequities are clearly conceptualised within The Social Model of Disability that emphasises the myriad of social, economic and physical barriers that can restrict people's participation within society (Burchardt, 2004).

Corresponding author: Alexandra Martin (alexaamartin@gmail.com) 
Social inclusion is the process of improving the terms of participation in society through enhancing opportunities, access to resources, voice and respect for rights (Australian Social Inclusion Board, 2012). However recent research illustrate participation inequalities for people with disabilities within the community when compared to those without disabilities, signifying the continued existence of social exclusion. A qualitative case study explored the concept of participation from the perspectives of 63 people self-identifying with diverse disabilities, 31 male and 25 female, ranging from 18-70 years from Illinois and Colorado (Hammel et al., 2008). Focus groups yielded results that described participation as a dynamic negotiation between personal choice, such as a desire to focus on specific areas, and environmental influences such as availability of resources and supports. It was also a firmly held belief that the government and social policies need to ensure enforcement and compliance of their rights to equal access and opportunities (Hammel et al., 2008). Similarly, Raymond et al. (2014) purposively sought 12 older males and females in Québec with varying disabilities to participate in a case study across 10 months seeking to understand participant narratives regarding the aging population who experience disability and the notion of social participation. Findings support the contention of Hammel et al. (2008) whereby participation was described to occur through self-determination in conjunction with inclusive environments (Hammel et al., 2008; Raymond et al., 2014). Environmental barriers, particularly related to a lack of wheelchair access within social settings, were particularly noted to limit participation ability. It was concurred that individuals with a disability viewed their community participation as compromised, attributing this to the unavailability of equal access and opportunities within their environment (Hammel et al., 2008; Raymond et al., 2014). These studies illustrate the social exclusion that is experienced by people with a disability in regard to experiencing equal participation whilst concurrently highlighting the built environment as a barrier towards participation.

Supporting the contention that the built environment is a barrier towards participation, a large cross-sectional study conducted in the Netherlands used the Family Needs Inventory (Alsem et al., 2013) to identify the needs of 146 parents of children with a physical disability to enhance their child's participation (Piškur et al., 2015a). The built environment was recognised as the most frequent barrier towards achieving participation in the community whilst assistive technology, environmental adaptations, and facilities were determined the top three factors that enhance participation of their child. In a second small qualitative study, Piškur et al. (2015b) interviewed 13 parents of children with a disability to explore the lived experiences of enabling participation for their child. The notion that reduced participation results from restricted environments is reinforced (Piškur et al., 2015a; Piškur et al., 2015b; Raymond et al., 2014), particularly environments such as sanitary facilities, entrances, and stairs within both the school and in the broader community (Piškur et al., 2015b). Similarly in Australia, Bigby and Balandin's (2005) mixed methods study purposively sought 40 Victorian day and community services accessed by individuals with lifelong disabilities. The services reported that access to buildings and sanitary facilities were the most common barriers for individuals with a disability to participate in community leisure activities, alongside the need for additional space to accommodate wheelchairs. These studies ascertain that barriers exist within the built environment and restrict equal participation for people with a disability, whilst collectively placing an emphasis upon sanitary facilities as a distinct built environment impacting participation.

The Convention on the Rights of Persons with Disabilities (CRPD) is an international agreement which outlines aspirations to promote, protect and ensure full and equal enjoyment of all human rights whilst promoting respect for inherent dignity by all persons with disabilities (United Nations [UN], 2006). Congruent with promoting social inclusion through the built environment, Article 9 of the CRPD asserts appropriate measures should be taken to ensure persons with disabilities have access, on an equal basis with others, to 
the physical environment, transportation, information and communications (UN, 2006). A mixed methods study within Victoria purposively sought 100 adult participants with a range of physical disabilities. Participants rated their levels of satisfaction and difficulty across a range of activities and participation and detailed the impact of assistive technology within their lives (Watchorn \& Layton, 2011). This data was coded against rights articulated within the CRPD, with participant responses dictating whether a CRPD right was either achieved or failing (Watchorn \& Layton, 2011). Findings revealed 32 instances of CRPD Article 9 being unmet (Watchorn \& Layton, 2011), yet another indication that people with a disability experience participation inequalities attributed to the accessibility of environments.

In the year 2015 an estimated 4.3 million Australians were living with a disability, of such, 1.4 million identified with having a severe or profound limitation (Australian Bureau of Statistics, 2016). PricewaterhouseCoopers (2011) argue that the current environment, both government system and societal attitudes, does not offer people with a disability the same opportunities it does other Australians; it is disjointed, inequitable and massively underfunded. Therefore, people with a disability continually experience poorer results in levels of participation compared to their fellow citizens (PricewaterhouseCoopers, 2011). In conjunction with the CRPD aspiring to achieve equality for people with disabilities, The Australian Disability Discrimination Act 1992 (DDA) (Australian Federal Government, 2013) aims to eliminate discrimination against people with disabilities across several areas; particularly pertinent is the area regarding access to public premises. The DDA declares that it is unlawful for a person to discriminate against another person on the ground of disability by refusing to allow access to, or the use of, any premises that the public or a section of the public is entitled or allowed to enter or use (Australian Federal Government, 2013). To uphold anti-discrimination legislation the Building Code of Australia (Australian Building Codes Board, 2016) dictates access provisions required when building new public facilities. Herein, design for access and mobility is guided through the application of Australian Standards 1428.1-2009 (AS 1428.1-2009) (Standards Australia, 2010). This document specifically outlines a range of design requirements including minimum clearances, heights, fittings and circulation space (Standards Australia, 2010). Despite the existence of legislation and standards, the current research suggests access rights for people with disabilities continue to remain unmet (Watchorn \& Layton, 2011; Bigby \& Balandin, 2005).

For some people with more complex disabilities the sanitary facilities that meet Australian Standards are insufficient. In particular, the absence of changing facilities is noted to affect people with more complex disabilities when out in public (Australian Government Department of Industry, Innovation and Science, 2016). Although there is an absence of literature on this specific topic, it can be posited that an unmet need of appropriate sanitary facilities is likely to exclude the participation of people with complex disabilities in the social, cultural, civic, political and economic opportunities available within their communities (Australian Building Codes Board, 2018).

The Changing Places concept was initially founded in 2003 in the United Kingdom (UK), as an attempt to increase sanitary facility accessibility for individuals with a severe and profound physical disability and their families/carers who experience difficulties when using standard accessible sanitary facilities (Changing Places, 2018). The design of Changing Places in the UK includes a full-sized change table, ceiling hoist, shower, and increased circulation space to meet the needs of people with significant and profound physical disabilities (Changing Places, 2018). Likewise, in Australia to be an accredited Changing Places facility, design features must include: a height-adjustable adult sized changing bench; a constant charging ceiling track hoist system; centrally located peninsula toilet; automatic door with a minimum clear opening of $950 \mathrm{~mm}$; circulation space and other fixtures and fittings as detailed in the design specifications (Changing Places Australia, 2017a) (refer to Figure 1). These features exceed what the Building Code of Australia currently requires as outlined in AS 1428.1-2009 (refer to Figure 2) for a public accessible sanitary facility. 
Current legislation requires that Changing Places facilities must always be provided in addition to an accessible sanitary facility that meets AS 1428.1-2009 as it is recognised that using Changing Places may take greater time thereby restrict use of facilities by others. Within Australia there have been multiple initiatives advocating for the installation of Changing Places facilities varying across the states. These initiatives have been successful with the construction of 29 facilities compliant with the Changing Places design standards (Changing Places Australia, 2017b). A further 52 'adult change facilities' exist; these include some components of the Changing Places design but do not meet the entire technical design standards (Changing Places Australia, 2017b).

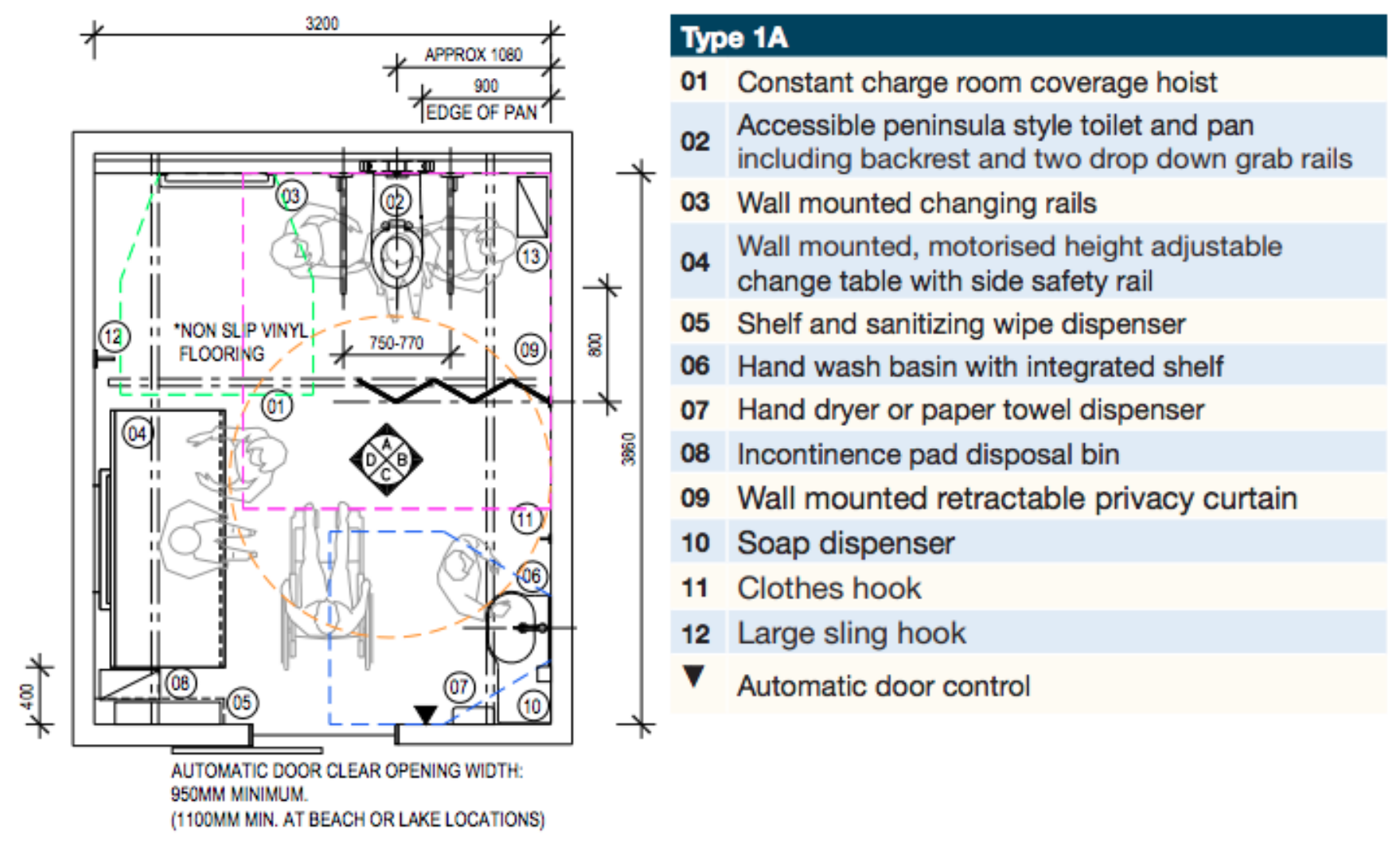

Figure 1.

Changing Places Type 1a Design - Example of Changing Places facility layout (Changing Places, (2017a). Copied

bv Deakin Universitv School of Health \& Social Develonment with permission. 


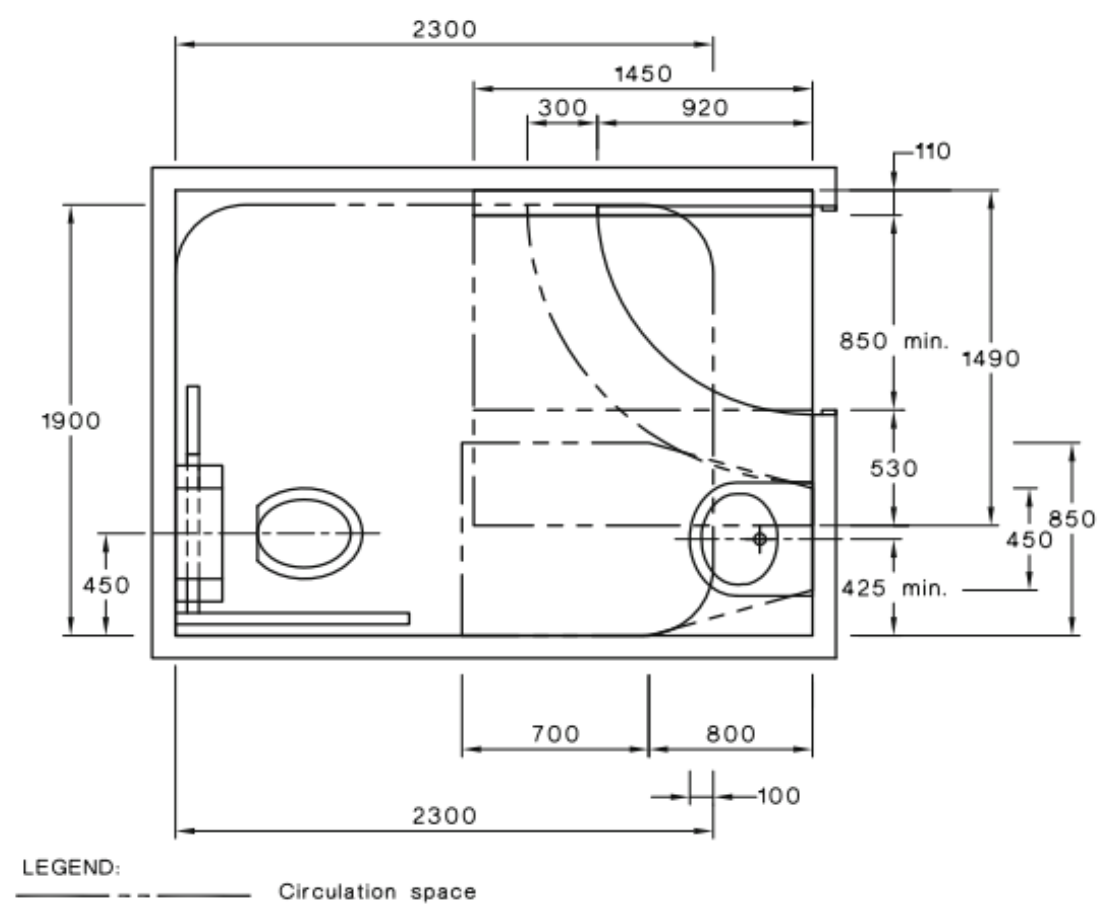

DIMENSIONS IN MILLIMETRES

Figure 2.

AS 1428.1-2009 Figure 52 - Example of sanitary facility layout (Standards Australia, 2010, p. 89). ( Standards Australia Limited. Copied by Deakin University School of Health \& Social Development with the permission of Standards Australia under Licence 1806-c060.

Currently there is limited evidence pertaining to the use of Changing Places facilities within Australia. A survey was conducted in Western Australia capturing the responses from 642 rural and metropolitan participants to assist in determining preferences for Changing Places locations. People with a disability made up 20 per cent of the participant sample, alongside 80 per cent of participants identifying as carers and disability service organisations that support people to use Changing Places facilities (Disability Services Commission, 2015). Findings depicted that participants viewed Changing Places as an enabler to participation and that there was a need for Changing Places to be located at shopping centres, central business districts, airports, beaches and entertainment areas. A recent grant was released within Victoria providing $\$ 2$ million to fund the construction of 20 Changing Places facilities within the state; secondary to this, an online survey was released seeking to identify where Changing Places facilities were most needed (Australian Government Department of Health and Human Services, 2017). Results yielded over 1,300 respondents, of which 75 per cent of respondents had used or assisted someone to use a Changing Places facility. Again, results focused on preferred locations of future Changing Places facilities. This research currently comprises the body of literature available concerning the use of Changing Places facilities within Australia. Given this, there is expansive knowledge to be gained from further research and exploration to contribute to the body of knowledge surrounding the use of Changing Places within Australia.

At the time of conducting this study there had been no published research within Australia to qualitatively explore the use of Changing Places. The aim of this study was to explore the lived experiences of people who use Changing Places facilities within Victoria. The study 
aimed to explore and provide greater insight into how the facilities and their specific design features are used and perceived by people who experience disability and their carers. Such information may contribute to the future development of Changing Places sanitary facilities both in Australia and internationally.

\section{Method}

\section{Research Design}

Two researchers conducted this study in 2016, approved by the Deakin University Human Research Ethics Committee (reference 2016-186) on August $10^{\text {th }}$ 2016. A qualitative phenomenological research design was employed to collect rich in-depth information from participants (Corbin \& Strauss, 2008). Qualitative research has been described as particularly beneficial in gaining a deeper understanding of specific user needs and experiences (Begay, Lee, Martin \& Ray, 2004). Finlay and Ballinger (2006) describe phenomenology as both a philosophy and an approach to research that allows in-depth exploration of how phenomena appear and the interpreted meaning of such phenomena. A phenomenological approach was selected as currently there is little known about the use of Changing Places within Australia and phenomenology allows for the lived experiences of Changing Places users to be thoroughly explored and documented.

\section{Sample Method and Recruitment}

Participants were recruited through purposive and snowball sampling. Purposive sampling was employed as the researchers sought to deliberately select individuals based on predefined criteria (DePoy \& Gitlin, 2005). Snowball sampling was also used whereby participants were encouraged to invite others to participate in the study (DePoy \& Gitlin, 2005). This method was included to broaden possible participant catchment.

Inclusion criteria for this study was specified as being 18 years and over; able to independently provide informed consent; and having used a Victorian Changing Places sanitary facility within the previous six months. The inclusion criteria allowed participation eligibility to be extended to people with disabilities as well as their families and/or carers who may assist with using the facilities.

Two strategies were employed for the recruitment process. The first strategy involved direct advertising through posters. The researcher approached facility or site managers of Changing Places facilities via email and in person, requesting permission to place posters advertising for participants within the Changing Places facilities. Online advertising through relevant professional networks and social media was also used. The second strategy included the process of snowball sampling and networking through users and relevant professionals.

\section{Informed Consent}

A plain language statement and consent form was developed explaining the aim, purpose and participant requirements of the study. To maximise understanding by the general population the plain language statement was written at a sixth to eighth grade level, excluded the use of jargon and avoided abbreviations (DePoy \& Gitlin, 2005). Consent forms were designed to be independently completed by a participant, and excluded the option of gaining third party consent in attempt to deter participants who would not meet the inclusion criteria to provide independent informed consent. These forms were provided to potential participants through email or a hard copy within the mail with a reply-paid envelope, depending upon participant preference. To assess the understanding of all individuals when participating in research, particularly those with intellectual disabilities who have been recognised as vulnerable persons in research (DePoy \& Gitlin, 2005), a set of questions was 
administered through a phone call with the researcher prior to commencing the interview. The questions were sourced from Horner-Johnson and Bailey (2013) and are as follows:

(1) Please tell me, in your own words, what is this study about?

(2) What will you be doing if you take part in this study?

(3) What are the risks of being in this study?

(4) When I say your taking part is completely voluntary, what does that mean to you?

(5) When I say that your answers will be kept confidential, what does that mean you?

(6) What can you do if you start the study but don't want to finish it?

Although not occurring within this study, if responses to these questions were not adequate the possibility to participate was declined.

\section{Participants}

A total of four Changing Places users participated in the study. All participants were female, aged between 34-64 years (mean age: 52; standard deviation: 14), spoke English as their first language, and lived in the Eastern suburbs of Melbourne or regional Victoria. Participants identified across three categories of users: independent and direct user; carer of a person with a disability; and family member of a person with a disability. Participant One identified as a support worker for people with disabilities; Participant Two identified as a mother of a child with a physical disability; Participant Three identified as a person with a physical disability; and Participant Four identified as a mother of an adult child with a physical disability.

\section{Interview Guide}

Semi-structured interviews were used to collect data allowing participants to discuss topics they regarded as significant and provide their own version of an experience (Denscombe, 2014). A list of questions and topics was generated to guide the interview process. This was informed by themes in existing literature and identified gaps in knowledge. This interview guide was electronically provided to an access consultant and a disability advocacy informant, asking for comment and suggestions regarding current gaps in knowledge surrounding Changing Places. The interview guide was piloted amongst 10 adults aged between 20-65 years and modifications including phrasing of questions and removal of similar questions were adjusted as required. The interview guide consisted of twenty questions. The questions addressed broad areas relating to Changing Places, including facility features, layout, comparison between Changing Places and alternative sanitary facility options, if Changing Places influences community access and inclusion, and the Changing Places symbol, i.e. 'What does the presence of the Changing Places symbol mean to you?' The interview guide contained two images for reference within the interview: a Changing Places peninsula pan and an AS 1428.1-2009 toilet pan (Australian Building Codes Board, 2016). The interview guide assisted the researcher as a prompt for discussion across broad and varying topics, however the researcher was not required to strictly adhere to the guide since interviews were semi-structured and exploratory in nature (DePoy \& Gitlin, 2005).

Participants were asked to complete a demographic form at the beginning of the interview outlining their age, residential postcode, gender, their roles when using Changing Places, and whether they identified as having a disability. If the interview was conducted via telephone, the researcher verbally asked the demographic questions and recorded participant responses. Images of the Changing Places peninsula pan and AS 1428.1-2009 toilet pan contained within the interview guide were emailed to the participant if the interview was conducted via telephone. 


\section{Data Collection}

One researcher conducted all of the interviews. One interview was conducted face-to-face at a Deakin University campus and three interviews were conducted via telephone; the method of interview was decided from participant preference. The interview guide was present throughout each interview and utilised as a prompt for the researcher. Interviews were audio recorded and transcribed verbatim within two weeks post interview.

\section{Data Analysis}

Thematic analysis was employed to identify themes amongst the interview transcripts using an inductive approach, seeking codes and themes within the data (Braun \& Clarke, 2006). Thematic analysis was performed across the following six phases as described by Braun and Clarke (2006). Phase One commenced during the initial data collection and transcription process whereby both researchers reflected upon information received in the interview. Phase Two involved both researchers independently and thoroughly reading each transcript to become immersed within the data (Braun \& Clarke, 2006). Each transcript was printed on different coloured paper followed by a coding process to identify features that addressed the research aim through highlighting and writing within the margins of each transcript. Phase Three involved collating the individual codes into themes (Braun \& Clarke, 2006); this was achieved by typing the codes into an Excel spreadsheet and cross checking the codes with the original transcript. During Phase Four each theme was reviewed and refined through conversations between the two researchers. Phase Five identified each theme title and concluded the scope of the theme through discussion between the researchers. Phase Six involved presenting the findings in written format; once initially written, the researchers fluctuated between phase five and phase six to clearly define the scope of each theme and ensure the data was accurately represented (Braun \& Clarke, 2006).

\section{Findings}

After a thorough analysis of each interview transcript, four main themes emerged describing the experiences of Changing Places users. These were: 'People Using Changing Places'; 'The Accessibility of Sanitary Facilities'; 'Changing Places and the Built Environment'; and 'Community Participation'. These are outlined below.

\section{People Using Changing Places}

Each participant presented with varying personal characteristics when being a user of Changing Places facilities, highlighting how each user individually and uniquely interacts with the Changing Places environment.

Participant One identified as a support worker who assisted multiple people with varying disabilities to use the facility. The diverse characteristics of people assisted by Participant One were described in terms of physical abilities: "Some people can't sit on a toilet, they don't have the body control, head control, upper body control to sit. Or they don't have lower body control to actually be able to use a toilet. Some people are continent and need to go to the toilet and can't stand, depending on their disability they don't have the upper body strength to transfer themselves". Participant Two and Participant Four were mothers of children with a disability who used the facilities with their assistance. One mother used the facility with her young son and primarily used a stroller when mobilising within the community. Transfers to the change table involved physically lifting her son from the stroller. The second mother used Changing Places with her adult son who used a manual wheelchair to mobilise within the community. Transfers to the change table were described to occur through a combination of standing pivot transfer, partial weight bearing and physical lifting 
support. In this instance, both the mother and the child were simultaneous users of the facility however their interactions within the same environment varied drastically. Participant Three identified as an independent user of the facility, using either a manual or powered wheelchair when mobilising within the community. Transfers to the toilet were completed independently, with the aid of grab rails.

Each participant used the Changing Places environment in a unique manner; subject to their own ability and/or the ability of the individual they were assisting.

\section{The Accessibility of Sanitary Facilities}

Participants identified different methods in which they utilised facilities for their toileting needs. All four participants highlighted their use of standard accessible sanitary facilities, or "disability toilets", when in the community. Participant Four explained "I would usually do it [assist a person to change a continence aid] in a disabled toilet. But it wouldn't matter because what you and I know as a disabled toilet just has a bar and it's totally useless for someone like an adult that you're changing". Participant One and Participant Four explained that they have both used the floor of standard accessible sanitary facilities as an area to change or clean another person. This option was described as "disgusting", "unfair" and "unhygienic". In both instances, each participant explained lifting a person up and down from the floor as an extremely difficult process that caused pain to their back and often required assistance or further support from family members or staff.

Participants also identified using alternative options when standard sanitary facilities were not accessible for their toileting needs, such as changing continence aids or sitting on the toilet. Three participants described using a vehicle, either on a seat or in the back of the vehicle, as an area to change or clean a person when they were "really stuck" for an accessible sanitary facility alternative. This option was described as "far from ideal", "difficult" and "awkward". Participant Four explained that when attending hospital appointments in Melbourne they had used a height adjustable bed within the appointment rooms to lay her son down to be changed. This option was described as "quite good because they go up and down" and comparable to the change table design feature within Changing Places. But when hospital staff did not offer these facilities, the floor of a sanitary facility was the only option. The last option identified by all participants, when there was no access to a sanitary facility or suitable alternative to accommodate toileting needs, was to leave the venue and return home; all participants reported experiences with this situation or similar.

Alongside outlining how standard accessible sanitary facilities and other toileting options were used, participants discussed a general lack of public understanding in regard to accessibility, specifically their sanitary facility needs. "Accessibility" was depicted as a broad term varying in definition according to different people, "some places, even though they think they are accessible, have lots of obstacles in the way" [Participant One]. Participant Three explained the inaccessible situation, "even if you go to a restaurant they say 'oh yes there's an accessible toilet', and you get there and you can't even get your wheelchair in", whilst Participant One highlighted "their intentions are good but the application is not there". Participants spoke negatively of experiences with "inaccessible accessible facilities", using terms such as "not good enough" and "unfair" to express their feelings. There was an understanding across all four participants that unless placed in the situation of having a disability or caring and supporting an individual with a significant physical disability "people don't know" and "it's just ignorance". Participant Two depicted this concept explaining "I had never thought of this before my son was born, it had never occurred to me that people would need this, it's just not a part of your experience, you just don't think of it".

As a collective, participants described the accessibility of Changing Places through the design features specific to Changing Places which included the ceiling track hoist, change table, circulation space, peninsula toilet pan, shower, Master Locksmith Access Key (MLAK), 
often referred to as "MLAK key" and the Changing Places symbol.

Participant One utilises the hoist and expressed satisfaction in regard to the positioning over the toilet pan and change table as it resulted in reduced manual handling. The hoist was also valued as a feature that "can offer independence for someone who can use the hoist themselves" [Participant One]. All participants depicted the hoist as a feature that was "needed" within Changing Places facilities.

Three participants discussed using the change table meant using sanitary facilities "would be quicker" and removes the 'strain' of getting "people onto and up off the floor" and "your back getting effected". Both Participant One and Participant Three described the change table as a "needed" feature within the facilities.

The increased circulation space, when compared to standard accessible sanitary facilities, was referred to as "satisfying" and "needed" by each participant. The increased space "gives you much more room to be able to manoeuvre with two people" [Participant One]. Participant Three stated "I was able to move around it easily, access everything real easy". Participant One mused "even if you're not using all of the facilities, you still have more space around you", encapsulating the importance of adequate circulation space.

The peninsula toilet pan (refer to Figure 1) was explored in detail by the researcher as this feature significantly differs from standard accessible sanitary facility toilet pans. All four participants expressed a preference for the peninsula toilet pan that Changing Places features. Participants explained that the peninsula pan makes it "easier" to access the toilet compared to standard accessible sanitary facilities where support is typically provided on one side making it "harder to get in there and use the proper lifting technique" for carers. It was also recognised that standard accessible sanitary facilities "isolates someone who has hemiplegia" [Participant One]. Overall, the peninsula pan was described to "meet more needs across the board" [Participant One].

MLAK is a key system that enables people with a disability to gain access to a network of public facilities (Master Locksmiths Association of Australasia [MLAA], 2017). Eligibility is restricted to people who have a disability and received written approval from a relative authority, individuals are then required to submit an application form and pay a purchase fee to receive the key (MLAA, 2017). Participants described both disadvantages and advantages of the MLAK system. Participant One explained a disadvantage of the MLAK system, stating "I guess if you don't have an MLAK key with you, you're stuffed...some people don't have or haven't obtained MLAK keys". Participant Two described feeling "surprised" when initially discovering a key was required to access the facility, stating "...you don't need a key to get to other public toilets so it's a bit strange that you would need one to get to the Changing Places facilities". This disadvantage was offset by all four participants as they discussed advantages of the MLAK system, "...it's just as important to have a facility, and also have it available for people who really need it" [Participant Four]; "you don't want people who don't need it just wandering in because it's a spare toilet...you want to keep it for the people that need it so that it's free and clean and available" [Participant Three]. The MLAK system also meant the facilities and features were protected from being "vandalised" and "kept in a better state for people who need it" [Participant One].

Three of the four participants acknowledged that they were unaware of the Changing Places symbol, yet when prompted by the researcher a "vague image came to mind". Despite being unable to recall the symbol independently, positive meaning was attributed to the symbol and endorsed by each participant. Participants described the symbol to represent the design features of Changing Places, "if it's accredited you know it's to a certain standard...you know what you're going to get" [Participant One]. All participants indicated the symbol informed them that the facilities "would be very usable" and are "going to be accessible". The symbol "would mean I know where to go for a proper toilet, to be totally comfortable and I know it's 
going to be clean and it's going to be accessible". Overall, the descriptions provided about the symbol depicted Changing Places as an accessible sanitary facility that meets the needs of users. Participant Two concluded "it's very welcoming, I suppose, you know there is going to be the equipment available that we need to be able to look after my son".

\section{Changing Places and the Built Environment}

Each participant broadly identified venues where they had used Changing Places facilities. These included "shopping centres", "council city centre", "swimming pools" and a "Melbourne train station". These venues were also identified as places that participants felt that both additional and new Changing Places needed to be installed. Participant One mentioned being pleased with the opening of two Changing Places within one shopping centre venue, but highlighted in contradiction "in some ways we shouldn't be excited about it, it should just be standard". Participant Two continued "...it's just terrible that there's so much space and money lurking around there and they're just not doing it...but so many people I know need these facilities" [Participant Three]. Each participant also stated there were not enough locations or venues that provided Changing Places; Participant One explained: "I guess everywhere should have a Changing Places toilet, much more than what they already do". Hospitals were identified as a specific venue in which there were no known Changing Places and the standard accessible sanitary facilities did not accommodate the needs of people with multiple and complex disabilities. Participant Four explained "there's huge issues with having a disabled child, let alone not being able to change them, and especially in a hospital...that really gets to me more than anywhere". There was an underlying expectation that hospital facilities should provide appropriate facilities to be used by people with disabilities.

\section{Community Participation}

Participants described the need to "plan" community participation around their ability to access usable sanitary facilities, expressing concern "will I get somewhere and be able to use a toilet if I need to" [Participant One]. Participant Four exemplified the difficulty: "It's not something that you would just wander around and think oh I hope I can find a toilet for him because you know there are none...I would definitely plan around it'. Participant Three surmised "I try to know where they are...so yes, I always have to plan when I need to go to the toilet before I need to go".

All four participants positively spoke about the impact Changing Places has on their access to the community. Changing Places was depicted as a facility "making society more accessible for more people with a range of disabilities" [Participant One]. Participants described the presence of Changing Places as enabling those who use the facility and have a disability. Users were "able to do the same things that everyone else does without having to worry about getting home or accidents happening" [Participant One]. Participants felt that Changing Places enhanced equal participation within their communities through being an environment that provided a typical sanitary facility experience amongst daily activities for people with physical disabilities:

We can get in and out quicker as well, so they can get back to doing whatever it is that we're out doing; playing at the park, walking around the lake, going shopping, you know, going to the movies, whatever it is they can just get back to being. [Participant One]

\section{Discussion}

The design of the built environment is a critical determinant of a person's ability to participate within their home and community regardless of their age, gender or abilities (Watchorn, Larkin, Hitch and Ang, 2014). The eminent article Shut Out: The Experience of People with Disabilities and their Families in Australia (Australian Government Department of Social 
Services, 2012) reported more than 27 per cent of the 750 respondents stated that lack of access to the environment acts as a barrier to their full participation in community life. These environmental barriers towards community participation can be seen as a risk factor for experiencing social exclusion, which is known to have detrimental effects on the physical and mental health of an individual (World Health Organization, 2003). Although there has been recent advancements in legislative and social drivers towards designing built environments which are inclusive for all, it is acknowledged that there continues to be many people unable to participate in their desired or required life roles due to inaccessible environmental design (Watchorn, Larkin, Hitch and Ang, 2014). Participants within this study, who identified as having a profound physical disability or as a family member/carer of a person with a significant/profound physical disability, each highlighted the "inaccessibility" of standard sanitary facilities available within their communities in Victoria. This "inaccessibility" has been described to result from a lack of necessary equipment, space and public understanding, aspects endorsed through comparisons drawn between various sanitary facilities by participants within this study. Participant Four declared "a disabled toilet just has a bar and it's totally useless for someone like an adult that you're changing" whilst Participant Three expressed "sometimes you can't turn your chair around in them" - two clear portrayals regarding the inadequacy of standard accessible sanitary facilities meeting the needs of people with severe and profound physical disabilities and their carers/families. These results are synonymous with previous findings which suggested the most common barrier for people with a disability more broadly to participate within the community was the ability to access buildings and toilets, as well as a lack of additional space needed to accommodate wheelchairs and equipment (Bigby \& Balandin, 2005). This also resonates with findings from Watchorn and Layton (2011) that described a series of instances in which the current Australian building standards for accessibility did not meet the needs of people with a disability. Findings implied that despite the existence, growth and recognition of standards and legislation, they currently are not enforced adequately or do not meet the needs of those with severe and profound physical disabilities (Watchorn \& Layton, 2011). This is comparable to participants describing their negative experiences with standard accessible sanitary facilities within this study. This calls attention to the inaccessibility of standard accessible sanitary facility environments whilst further emphasising that the current building standards and legislation do not fulfil needs of the population with a significant physical disability.

It has long been contended that disability can be alleviated through adoption of public policies requiring all buildings to be accessible (Mace, Hardie \& Plaice, 1991). Despite this concept being acknowledged more than 20 years prior to this study, recent and relevant literature continues to assert that current building standards and policies do not achieve accessibility for people with severe and profound physical disabilities thus contributing to the high prevalence of social exclusion and marginalisation of people a disability (Australian Government Department of Social Services, 2012). Article 9 of the CRPD specifically dictates obligations to take appropriate measures to ensure equality of access for people with a disability (United Nations, 2006). The recent research contained within Disability Rights Now, the Civil Society Report on the United Nations Convention on the Rights of Persons with Disabilities highlighted gaps in Australian government compliance with the CRPD from the perspectives of people with disabilities, representative and advocacy organisations involved with the protection of human rights (Disability Representative, Advocacy, Legal and Human Rights Organisations, 2012). The Disability Rights Now report announced that the Australian National Disability Strategy (2010-2020) was devised with the intent to implement obligations under CRPD Article 9. However, the current commitments adhere to standards outlined within the Disability Discrimination Act 1992 which were developed prior to the CRPD and subsequently do not address all barriers to access covered within the CRPD. As such, Disability Rights Now recommended that the National Disability Strategy (2010-2020) must incorporate measures to address the full range of accessibility obligations within the CRPD Article 9 (Disability Representative, Advocacy, 
Legal and Human Rights Organisations, 2012). These recommendations support participant discussion within this study whereby participants described the need for Changing Places facilities to be included within the Building Code of Australia (Australian Building Codes Board, 2016), specifically in regards to buildings undergoing renovations, new buildings, and large public facilities. Significant disappointment was particularly expressed regarding the inaccessibility of hospital sanitary facilities for people with disabilities, and a strong emphasis was placed on the need to incorporate Changing Places within new hospital design or renovation. Incorporating Changing Places within the Building Code of Australia (Australian Building Codes Board, 2016) and AS 1428.1-2009 (Standards Australia, 2010) aligns with the belief that government and social policies need to ensure enforcement and compliance of rights to equal access (Hammel et al., 2008), and could be seen as a measure taken towards achieving equality outlined within the CRPD.

Findings from this study provide insight into the experiences and perceptions of people using Changing Places sanitary facilities and contribute to literature in this field. Additionally, findings from this study consolidate previous research regarding environmental inequities continue to be experienced by those with disabilities, their families and carers. It is anticipated that the findings will contribute to a knowledge base for further development of Changing Places facilities, and create awareness of how the facilities enhance opportunities for social inclusion and enable participation and performance for people with physical disabilities when accessing the community. Furthering this understanding can support future work towards meeting equality standards outlined within the CRPD and achieving equal social inclusion for people with severe and profound physical disabilities, their families, and their carers. It is unacceptable that people with disabilities and their families and carers must continue to use "dirty, cold, tiled floors" of public sanitary facilities due to the absence of appropriate alternatives in key community settings. In so doing, the dignity, hygiene and safety of individuals is severely compromised or, where people avoid using community facilities due to the absence of appropriate sanitary facilities, people continue to face social exclusion and non-participation. Changing Places provides an alternative facility supporting the concept of a socially inclusive environment, whilst allowing for people with a severe and profound physical disability to maintain dignity and safety when using public sanitary facilities.

\section{Limitations}

Limitations are noted within this study. Firstly, the small sample size of four participants reduces generalisability of the findings to a wider population. Significant efforts were made to increase the sample size, including secondary advertising online and consistently ensuring posters remained displayed in facilities throughout the recruitment period. However, reduced time was available for the recruitment of participants and data collection process due to difficulties encumbered when gaining approval from the ethics committee as individuals with a disability are recognised as vulnerable persons in research. To combat this setback, inclusion criteria required participants to provide independent informed consent. Consequently, this excluded people with a disability who are unable to provide independent informed consent, limiting the voice of Changing Places users. Some mitigation of the small sample size arises when factoring one participant supported multiple people to use the facilities therefore providing insight from numerous perspectives.

Within the small sample size there was diversity amongst the characteristics of participants, despite this diversity reducing generalisability of research findings, it has provided rich data from a range of facility users thereby highlighting and describing the broad range of users who need Changing Places.

This study contains information specific to Australian legislation and building standards and therefore may or may not be relevant to international contexts. Lastly, it is important to 
acknowledge the relatively new skills of one researcher that could potentially be influenced by personal bias despite attempts to remain neutral throughout the interview process and inclusion of triangulation within the data analysis process.

Despite these limitations, this study provides valuable early insights into the use of Changing Places and maintains many research strengths that are prominent throughout the methodology whereby researchers ensured all attempts to meet aspects of trustworthiness were incorporated throughout the study.

\section{Recommendations for Further Research}

It would be valuable for future research to include a greater sample size and inclusion of participants unable to provide independent informed consent to continue bridging gaps in knowledge. It would be beneficial to include quantitative data focusing on user statistics to gain a broader understanding of those who use the facilities. Additionally, the use of qualitative data would be beneficial to explore the experiences of people with a disability using standard accessible sanitary facilities. It would also be advantageous to explore the concept of current standards not meeting the needs of people with severe and profound physical disabilities to assist with initiating a change in the current standards to include an accessible design for a broader range of abilities.

\section{Conclusion}

This explorative study has provided preliminary research to begin investigating the topic of Changing Places and contribute to the gap in knowledge regarding Australia's Changing Places facilities. The findings of this study further consolidate the existing research regarding environmental inequities and the inadequacy of current access standards experienced by those with disabilities, their families and carers. It is anticipated that the findings will assist with providing a knowledge base for Changing Places, creating awareness surrounding how the facilities enable participation and performance whilst enhancing social inclusion for people with physical disabilities when accessing the community. Furthering this understanding can support the future development of Changing Places facilities within Australia and initiating a national introduction of the Changing Places design as a response towards meeting CRPD equality standards.

\section{Acknowledgments}

Warm acknowledgments are extended to The Association for Children with a Disability and Helen Fearn-Wannan (Architecture \& Access). This research was able to flourish with your assistance and contribution towards the study. To each participant, thank you for sharing your time and experiences. Your personal insights were invaluable to this research. 


\section{References}

Alsem, M. W., Siebes, R. C., Gorter, J. W., Jongmans, M. J., Nijhuis, B. G. J. \& Ketelaar, M. (2013). Assessment of family needs in children with physical disabilities: Development of a family needs inventory. Child: Care, Health and Development. doi:10.1111/cch.12093

Australian Building Codes Board. (2016). National construction code, 2016, volume two. Retrieved from http://www.abcb.gov.au/Resources/Publications/NCC/NCC2016-Volume-Two

Australian Building Codes Board (2018). Accessible adult change facilities in public buildings: Consultation regulation impact statement. (2018). Retrieved from file:///Users/Lex/Downloads/Consultation_RIS_Accessible_adult_change_facilities_in public_buildings.pdf

Australian Bureau of Statistics. (2016). Disability, ageing and carers, Australia: First results, 2015. Retrieved from http://www.abs.gov.au/ausstats/abs@.nsf/mf/4430.0.10.001

Australian Federal Government. (2013). Disability discrimination act 1992. Retrieved from https://www.legislation.gov.au/Details/C2013C00022

Australian Government Department of Health and Human Services. (2017). Changing Places funding. Retrieved from https://providers.dhhs.vic.gov.au/changing-placesfunding

Australian Government Department of Industry, Innovation and Science. (2016). Review of the disability (Access to premises - buildings) standards 2010: First review. Retrieved

from https://industry.gov.au/industry/IndustrySectors/buildingandconstruction/Documents/ Review-of-the-Premises-Standards-Report.PDF

Australian Government Department of Social Services. (2012). Shut out: The experience of people with disabilities and their families in Australia. Retrieved from https://www.dss.gov.au/our-responsibilities/disability-and-carers/publicationsarticles/policy-research/shut-out-the-experience-of-people-with-disabilities-and-theirfamilies-in-australia?HTML\#2.5.1

Australian Social Inclusion Board. (2012). Social inclusion in Australia: How Australia is faring, 2nd edition. Retrieved from http://library.bsl.org.au/jspui/bitstream/1/3170/1/Social\%20inclusion\%20in\%20Austral ia\%20how\%20Australia\%20is\%20faring2012.pdf

Begay, W., Lee, D. R., \& Martin, R. (2004). Quantifying qualitative data: Using LibQUAL+ comments for library-wide planning activities at the university of Arizona. Journal of Library Administration, 40(4), 111-119. doi:10.1300/J111v40n03_09

Bigby, C., \& Balandin, S. (2005). Another minority group: Use of aged care day programs and community leisure services by older people with lifelong disability. Australasian Journal on Ageing, 24(1), 14-18. Retrieved from http://eds.a.ebscohost.com.ezproxyb.deakin.edu.au/eds/pdfviewer/pdfviewer?sid=24 4b731a-5a9b-4b85-b4651040bc540db1\%40sessionmgr4002\&vid=7\&hid=4103

Braun, V., \& Clarke, V. (2006). Using thematic analysis in psychology. Qualitative Research in Psychology, 3(2), 77-101. doi:10.1191/1478088706qp063oa

Burchardt, T. (2004). Capabilities and disability: The capabilities framework and the social model of disability. Disability \& Society, 19(7), 735751.doi:10.1080/0968759042000 284213

Changing Places. (2018). Changing places. Retrieved from http://www.changing-places.org/

Changing Places Australia. (2017a). Information guide \& technical standard. Retrieved from https://www.changing places.org.au/wp-content/uploads/2014/08/CHANGING-

PLACES-TECH-STANDARD-MAY-2017.pdf

Changing Places Australia. (2017b). About us. Retrieved from http://changingplaces.org.au

Corbin, J., \& Strauss, A. (2008). Basics of qualitative research: Techniques and procedures 
for developing grounded theory (3rd ed.). California: Sage Publications, Inc.

Denscombe, M. A. (2014). The good research guide: For small-scale social research projects. Maidenhead: Open University Press

DePoy, E., \& Gitlin, L. N. (2005). Introduction to research: Understanding and applying multiple strategies (3rd ed.). Philadelphia: Elsevier Mosby.

Disability Representative, Advocacy, Legal and Human Rights Organisations. (2012). Disability rights now, civil society report to the United Nations committee on the rights of persons with disabilities. Retrieved from http://www.ahrcentre.org/news/2012/10/ $19 / 433$

Disability Services Commission. (2015). Changing places improve community access.

Retrieved from http://www.disability.wa.gov.au/individuals-families-andcarers/forindividuals-families-and-carers/recreation-and-leisure-/changingplaces/

Finlay, L., \& Ballinger, C. (2006). Qualitative research for allied health professionals: Challenging choices. Chichester: Wiley.

Hammel, J., Magasi, S., Heinemann, A., Whiteneck, G., Bogner, J., \& Rodriguez, E. (2008). What does participation mean? An insider perspective from people with disabilities. Disability \& Rehabilitation, 30(19), 1445-1460. Retrieved from http://eds.b.ebscohost.com.ezproxyb.deakin.edu.au/eds/pdfviewer/pdfviewer?sid=1c 9d01c8-38b2-47aa-9b5ce9cf93bfdd38\%40sessionmgr103\&vid=5\&hid=120

Hammell, K. W. (2015). Quality of life, participation and occupational rights: A capabilities perspective. Australian Occupational Therapy Journal, 62(2), 78-85. doi:10.1111/1440-1630.12183

Horner-Johnson, W., \& Bailey, D. (2013). Assessing understanding and obtaining consent from adults with intellectual disabilities for a health promotion study. Journal of Policy and Practice in Intellectual Disabilities 10(3), 260-265. Retrieved from http://eds.b.ebscohost.com.ezproxyf.deakin.edu.au/eds/pdfviewer/pdfviewer?sid=b4e 7345e-7bb1-4c9a-b8fe-ac470bd7a045@sessionmgr104\&vid=5\&hid=119

Mace, R., Hardie, G., \& Plaice, J. (1991). Accessible environments: Toward universal design. In W. F. E. Preiser., J. C. Vischer., and E. T. White (Eds.). Design interventions: Toward a more humane architecture (pp. 155-176). New York: Van Nostrand Reinhold

Master Locksmiths Association of Australasia. (2017). Master locksmith access key (MLAK). Retrieved from https://www.masterlocksmiths.com.au/mlak.php

Piškur, B., Beurskens, A. J. H. M, Jongmans, M. J., Ketelaar, M., \& Smeets, R. J. E. M. (2015a). What do parents need to enhance participation of their school-aged child with a physical disability? A cross-sectional study in the Netherlands. Child: Care, Health and Development, 1, 84-92. doi:10.1111/cch.12145

Piškur, B., Meuser, S., Jongmans, M. J., Ketelaar, M., Smeets, R. J., Casparie, B. M., Haarsma, F. A., \& Beurskens, A. J. (2015b). The lived experience of parents enabling participation of their child with a physical disability at home, at school and in the community. Disability \& Rehabilitation, 38(8), 803-812. doi:10.3109/09638288.2015.1061612

PricewaterhouseCoopers. (2011). Disability expectations: Investing in a better life, a stronger Australia. Retrieved from https://www.pwc.com.au/industry/government/assets/disability-in-australia.pdf

Raymond, É., Grenier, A., \& Hanley, J., (2014). Community participation of older adults with disabilities. Journal of Community \& Applied Social Psychology, 24(1), 50-62.

Standards Australia. (2010). Australian standard: Design for access and mobility (AS 1428.1-2009). Sydney, NSW: Standards Australia

United Nations. (2006). Convention on the rights of persons with disabilities. Retrieved from https://www.un.org/development/desa/disabilities/convention-on-therights-of-personswith-disabilities/convention-on-the-rights-of-persons-withdisabilities-2.html

United Nations General Assembly. (1948). Universal declaration of human rights. Retrieved from http://www.un.org/en/universal-declaration-human-rights/

VicHealth. (2012). Disability and health inequalities in Australia: Research summary. 
Addressing the social and economic determinants of mental and physical health. Retrieved from https://disabilityemployment.org.au/file/3c98910c97782a8d4f6bf3ef6c3d207901fb6fd 4/vh disability summary web1.pdf

Watchorn., Larkin, H., Hitch, D., \& Ang, S. (2014). Promoting participation through the universal design of built environments: Making it happen. Journal of Social Inclusion, 5(2), 65-88.

Watchorn., \& Layton, N. (2011). Advocacy via human rights legislation: The application to assistive technology and accessible environments. Australian Journal of Human Rights, 17(1), 117-138.

World Health Organization. (2003). Social determinants of health: The solid facts $2^{\text {nd }}$ edition.

Retrieved

http://www.euro.who.int/_data/assets/pdf_file/0005/98438/e81384.pdf

\section{Biographical Notes}

Alexandra Martin completed a Bachelor of Occupational Therapy (Hons) in 2017 at Deakin University. Alexandra completed honours research and professional interest developed within human rights and equality for people with a disability, particularly in regard to the built environment and accessibility.

Valerie Watchorn is a lecturer in the Deakin University Occupational Therapy program. Valerie has worked as an Occupational Therapist in service provision and education both in Australia and overseas. Areas of professional interest include environmental design, universal design, assistive technology, occupational therapy practice education and teaching and learning within higher education.

Cathryn Grant is an Occupational Therapist and access consultant at Architecture \& Access. Cathryn has worked as an Occupational Therapist in hospital and community settings both in Australia and overseas. Her work as an access consultant involves assessing and providing advice on access to the built environment for people with a disability. 